\title{
Prognostic factors and outcomes of nonseminomatous germ cell tumours of testis-experience from a tertiary cancer centre in India
}

\author{
Lekha Madhavan Nair ${ }^{1}, \mathrm{~K}$ M Jagathnath Krishna², Aswin Kumar ${ }^{1}$, Susan Mathews ${ }^{1}$, John Joseph ${ }^{1}$ and Francis Vadakkumparambil James ${ }^{1}$ \\ ${ }^{1}$ Genitourinary Clinic, RCC, Thiruvananthapuram 695011, India \\ ${ }^{2}$ Department of Epidemiology and Biostatistics, RCC, Thiruvananthapuram 695011, India
}

\section{Abstract}

Germ cell tumour of the testis is the most common cancer in young men in the western world. India has the lowest incidence globally, and hence Indian data are sparse. We report the outcomes of patients with nonseminomatous germ cell tumours of testis treated at a tertiary cancer centre in South India over a period of 10 years. Patients with a histopathological diagnosis of nonseminomatous germ cell tumours of the testis from 1 January 2006 to 31 December 2016 were included in the study. Patient demographics, tumour characteristics and treatment details were retrieved from case records. KaplanMeier method was used to estimate progression-free survival (PFS) and overall survival (OS). Cox regression model was used to analyse the prognostic factors.

One hundred and nineteen patients with nonseminomatous germ cell tumours of the testis were included in the study. The median follow-up was 81 months. The estimated 4-year OS and progression-free survival were $87.1 \%$ and $84.5 \%$, respectively. The fouryear OS for good, intermediate and poor-risk groups was $93.6 \%, 87.5 \%$ and $52.6 \%$, respectively. The PFS at 4 years was $91.4 \%, 87.8 \%$ and $47.4 \%$ for good, intermediate and poor-risk groups, respectively. The presence of nonpulmonary visceral metastasis and biochemical response after chemotherapy were significant predictors for OS and PFS in multivariate cox proportional hazards regression. The survival figures are comparable to the rest of the world except in the poor prognostic risk group. The inferior survival noticed in this group of patients may be due to the lack of good salvage procedures. High-dose chemotherapy with stem-cell support may be considered more often for this group of patients.

Keywords: nonseminoma, germ cell tumours, testis, survival

\section{Introduction}

Testicular cancer accounts for $1 \%-2 \%$ of all malignancies in men. Ninety-five per cent of all testicular cancers are germ cell tumours [1]. Among these, about 50\% are nonseminomatous germ cell tumours (NSGCT). It is the most common cancer in young men in the western world. The age-standardised incidence rate of testicular cancer in India is 0.5 per 100,000 population, while it is 6.7 and 5.6 per 100,000 population for Europe and the United States, respectively [2]. India has the lowest incidence globally, and hence Indian

Correspondence to: Francis $\vee$ James Email: fvjames9@gmail.com

ecancer 2020, 14:1145

https://doi.org/10.3332/ecancer.2020.1145

Published: $18 / 11 / 2020$

Received: 25/07/2020

Publication costs for this article were supported by ecancer (UK Charity number 1176307).

Copyright: $($ ) the authors; licensee ecancermedicalscience. This is an Open Access article distributed under the terms of the Creative Commons Attribution License (http:// creativecommons.org/licenses/by/3.0), which permits unrestricted use, distribution, and reproduction in any medium, provided the original work is properly cited. 
data on testicular germ cell tumours are sparse [3-5]. Here, we report the outcomes of patients with NSGCT of testis treated at a tertiary cancer centre in South India over a period of 10 years.

\section{Patients and methods}

This retrospective study was conducted after getting approval from the Institutional Review Board. Patients with a histopathological diagnosis of nonseminomatous germ cell tumours of the testis from 1 January 2006 to 31 December 2016 were included in the study. Patients with age $\leq 15$ years were excluded from the study as they were treated in the Paediatric Oncology Department.

Patient demographics, tumour characteristics, stage of the disease, pre- and postorchidectomy tumour markers, histopathological features and treatment details were retrieved from case records. Patients were staged according to the UICC 7th edition TNM staging (Tumour, Node, Metastasis). For uniformity of reporting, patients from 2006 to 2009 were retrospectively staged according to the UICC 7th edition. Computed Tomography (CT) scan of thorax, abdomen, pelvis and serum tumour markers, namely, Alfa Feto Protein (AFP), $\beta$-human chorionic gonadotropin (HCG) and lactate dehydrogenase (LDH), were used for staging. Postorchidectomy tumour markers were estimated for the International Germ Cell Cancer Collaborative Group (IGCCCG) risk grouping [6].

\section{Treatment}

All patients underwent orchidectomy. One hundred and eleven patients underwent high-inguinal orchidectomy, and eight patients underwent scrotal orchidectomy. All stage IA and IB patients were given the options of chemotherapy versus active surveillance. Those patients who were willing to adhere to surveillance protocol were kept under active surveillance. Patients with stage IS disease received two or three cycles of BEP chemotherapy (Bleomycin 30 Units IV in $50 \mathrm{~mL}$ Normal Saline over 15 minutes on days 1, 8 and 15, Etoposide 100 mg/m²/ day IV infusion in 500ml Normal Saline on days 1 to 5 , Cisplatin $20 \mathrm{mg} / \mathrm{m}^{2} /$ day IV in $100 \mathrm{~mL}$ Normal Saline over 30 minutes on days 1 to 5 , repeated every 21 days). Stage II and III patients were treated according to the IGCCCG risk group. Good-risk patients received three cycles of BEP or four cycles of EP (Etoposide $100 \mathrm{mg} / \mathrm{m}^{2} /$ day IV infusion in $500 \mathrm{~mL}$ Normal Saline on days $1-5$, Cisplatin $20 \mathrm{mg} / \mathrm{m}^{2} / \mathrm{day}$ IV in $100 \mathrm{~mL}$ Normal Saline over 30 minutes on days 1-5, every 21 days). Intermediate- and poor-risk group received four cycles of BEP or four cycles of VIP (Etoposide $75 \mathrm{mg} / \mathrm{m} 2$ IV infusion on days 1-5, Ifosfamide $1.2 \mathrm{~g} / \mathrm{m} 2$ IV infusion on days 1-5, Cisplatin $20 \mathrm{mg} / \mathrm{m} 2 \mathrm{IV}$ infusion on days 1-5, Mesna $400 \mathrm{mg} / \mathrm{m} 2$ IV infused over $30 \mathrm{~min}$ before ifosfamide, then at 4 and 8 hours after the start of each ifosfamide dose, repeated every 21 days). The response was assessed with serial CT scans and tumour markers. Serum tumour markers, namely, AFP, $\beta$-HCG and LDH, were monitored every 3 weeks during chemotherapy and were repeated after 1 month of completion of chemotherapy. CT scan was done after 1 month of completion of chemotherapy in patients with a biochemical response. The radiological response was measured using RECIST criteria version 1.0. Patients in radiological and biochemical remission were kept on follow-up. Patients with normal serum tumour marker levels, but with residual retroperitoneal nodes more than $1 \mathrm{~cm}$ short-axis diameter, were considered for RPLND. Second-line chemotherapy was given for those with raised tumour markers.

\section{Follow-up}

Patients were followed up for 3 months with tumour markers and clinical examination during the first two years, 6 months up to 5 years and 1 year after that. Imaging was done every six months for two years. Patients on active surveillance were followed up according to the surveillance protocol. Clinical examination, serum tumour markers and chest X-ray were done every 2 months during the first year, every 3 months during the second year, every 4 months during the third year and every 6 months for years 4 and 5 . CT of thorax, abdomen and pelvis was done at 3 months, 12 months, 24 months and 36 months.

\section{Statistical methods}

Patient and tumour characteristics were analysed using descriptive statistics. Kaplan-Meier method was used to estimate progression-free survival (PFS) and overall survival (OS) and compared using the log-rank test. OS was calculated from the date of diagnosis to the date of 
death or last follow-up. PFS was computed from the date of diagnosis to the date of relapse or progression of disease or death. Cox regression model was used to analyse the prognostic factors. Statistical analysis was done using SPSS software version 11.0.

\section{Results}

One hundred and thirty patients were registered with a diagnosis of nonseminomatous germ cell tumours of the testis from 1 January 2006 to 31 December 2016. Among these, five patients came for a second opinion. Four patients abandoned the planned treatment, and one patient died before starting treatment. Only 119 patients completed the planned treatment and were included for final analysis. None of the patients was lost to follow-up. Follow-up was updated using clinical data and telephonic information. The median age at diagnosis was 27 years. The median tumour size was $6.0 \mathrm{~cm}$. Patient characteristics are summarised in Table 1.

One hundred eighteen patients underwent primary orchidectomy, while one patient had the surgery after completion of chemotherapy. Fifteen patients had a scrotal violation of which eight had scrotal orchidectomy while seven patients had prior trans-scrotal biopsy/aspiration. Three patients with stage IA disease were kept on active surveillance after orchidectomy. Patients who were considered unreliable for regular follow-up were given adjuvant chemotherapy. Two cycles of BEP were given for 22 patients with stage IA/IB. One course of BEP was given for a patient with stage IA disease. All patients with stage IS disease received two or three cycles of BEP. Among the stage II and III good risk patients, 27 received three cycles of BEP and one patient was treated with four cycles of EP. EP was given due to the non-availability of bleomycin during that time. Forty-four patients received four cycles of BEP for intermediate or poor-risk disease , and one patient was treated with our cycles of VIP (Bleomycin was avoided due to the presence of extensive bilateral lung metastases and a past history of smoking). Grade 3 or 4 neutropenia was documented in 12 patients. Eight patients developed bleomycin induced lung toxicity and were managed with oral prednisolone.

\section{Treatment response and relapse}

Among the 116 patients who underwent chemotherapy,106 achieved biochemical remission and 69 patients attained complete radiological remission. Twelve patients with residual radiological abnormality were kept on follow-up as there was a serial decrease in tumour size in the follow-up CT scans. Postchemotherapy retroperitoneal lymph node dissection (RPLND) was carried out for 14 patients with residual paraaortic nodes: five patients had mature teratoma; five had no viable tumour; four had viable tumour cells in the pathology specimen. Those with viable tumour cells on RPLND were given two more cycles of chemotherapy with VIP regimen. Patients with residual disease at multiple sites were not operated either due to nonacceptance by the patients or due to the increased risk of surgical complications. Six patients progressed after first-line chemotherapy and received second-line chemotherapy. Four of them received VIP (Etoposide, Ifosfamide, cisplatin), one patient received TIP (paclitaxel, ifosfaide, cisplatin) regimen and VelP (vinblastine, ifosfamide, cisplatin) was given for another patient as the second line. All the six patients progressed on second-line chemotherapy and eventually succumbed to the disease. Relapse was documented in four patients and lung was the most common site of relapse. Salvage chemotherapy was given for these patients, the regimens being VIP and TIP. Five patients developed brain metastasis, four received whole-brain radiotherapy (doses ranging from $30 \mathrm{~Gy}$ in 15 fractions to $40 \mathrm{~Gy}$ in 20 fractions), but none of them survived. The three patients who were kept on active surveillance did not show any evidence of recurrence. One patient developed a second primary malignancy - papillary carcinoma of the thyroid and another patient who received two cycles of BEP developed acute myeloid leukaemia after 1 year.

\section{Survival}

The median follow-up was 81 months (5 to 161 months). The estimated 4-year OS was $87.1 \%$ (Figure 1). Overall survival was $100 \%$ for stage IA and IB, 95\% for IS,86.7\% for stage II and 78.5\% for stage III disease. The 4-year OS for good, intermediate and the poor-risk groups were 93.6\%,87.5\% and 52.6\% respectively. No difference in survival was noticed for cryptorchidism, scrotal violation, presence of lymphovascular space invasion (LVSI), presence of seminomatous elements, yolk sac elements, choriocarcinoma components, presence of embryonal carcinoma in the surgical specimen or T stage. There was a significant difference in survival with respect to N stage, S stage, M stage and IGCCCG risk groups. Table 2 shows the differences in overall survival according to various groups. 
Table 1. Patient characteristics.

\begin{tabular}{|c|c|}
\hline Parameters & Number (percentage) \\
\hline $\begin{array}{l}\text { Age(years) } \\
<40 \\
\geq 40\end{array}$ & $\begin{array}{c}110(92.43) \\
9(7.56)\end{array}$ \\
\hline $\begin{array}{l}\text { Cryptorchidism } \\
\text { Yes } \\
\text { No }\end{array}$ & $\begin{array}{c}7(5.82) \\
112(94.11)\end{array}$ \\
\hline $\begin{array}{l}\text { Laterality } \\
\text { Right } \\
\text { Left }\end{array}$ & $\begin{array}{l}60(50.42) \\
59((49.57)\end{array}$ \\
\hline $\begin{array}{l}\text { Scrotal violation } \\
\text { Yes } \\
\text { No }\end{array}$ & $\begin{array}{c}15(12.6) \\
104(87.39)\end{array}$ \\
\hline $\begin{array}{l}\text { Seminomatous elements } \\
\text { Yolk sac components } \\
\text { Embryonal carcinoma components } \\
\text { Choriocarcinoma elements }\end{array}$ & $\begin{array}{l}31(26.1) \\
72(60.5) \\
68(57.1) \\
15(12.6)\end{array}$ \\
\hline $\begin{array}{l}\text { LVSIYes } \\
\text { No } \\
\text { Status unknown }\end{array}$ & $\begin{array}{c}16(13.44) \\
99(83.19) \\
4(3.36) \\
\end{array}$ \\
\hline $\begin{array}{l}\text { T stage } \\
\text { T1 } \\
\text { T2 } \\
\text { T3 } \\
\text { T4 }\end{array}$ & $\begin{array}{l}95(79.83) \\
14(11.76) \\
8(6.72) \\
2(1.68)\end{array}$ \\
\hline $\begin{array}{l}\text { N stage } \\
\text { N0 } \\
\text { N1 } \\
\text { N2 } \\
\text { N3 }\end{array}$ & $\begin{array}{l}55(46.21) \\
15(12.60) \\
27(22.68) \\
22(18.48)\end{array}$ \\
\hline $\begin{array}{l}\text { M stage } \\
\text { M0 } \\
\text { M1a } \\
\text { M1b }\end{array}$ & $\begin{array}{c}78(65.54) \\
30(25.21) \\
11(9.24) \\
\end{array}$ \\
\hline $\begin{array}{l}\text { S stage } \\
\text { S0 } \\
\text { S1 } \\
\text { S2 } \\
\text { S3 }\end{array}$ & $\begin{array}{l}33(27.73) \\
43(36.13) \\
30(25.21) \\
13(10.92)\end{array}$ \\
\hline $\begin{array}{l}\text { Composite stage } \\
\text { I } \\
\text { IS } \\
\text { II } \\
\text { III }\end{array}$ & $\begin{array}{l}26(21.84) \\
20(16.80) \\
15(12.60) \\
58(48.73)\end{array}$ \\
\hline $\begin{array}{l}\text { Risk group } \\
\text { Good } \\
\text { Intermediate } \\
\text { Poor }\end{array}$ & $\begin{array}{l}48(51.61) \\
26(27.95) \\
19(20.43)\end{array}$ \\
\hline
\end{tabular}




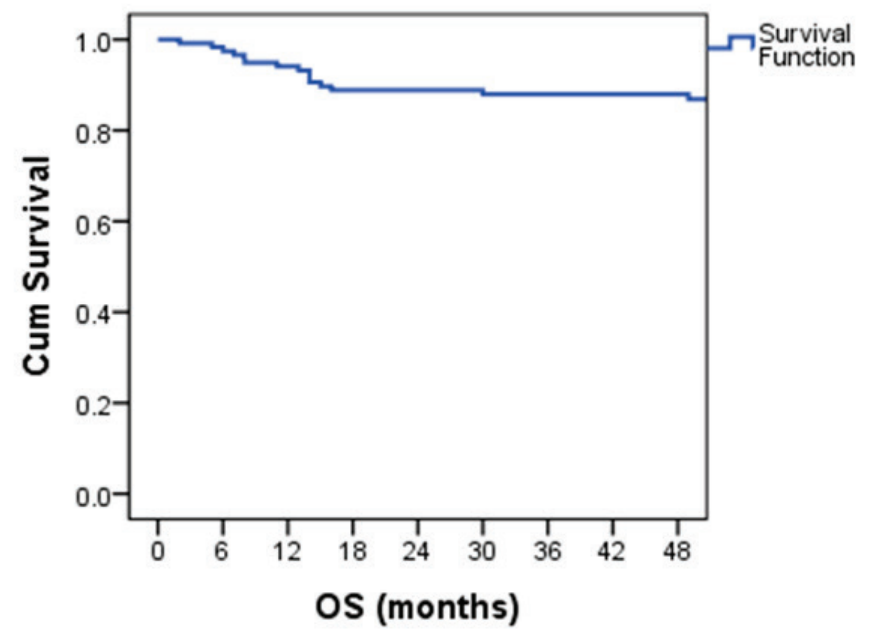

Figure 1. Kaplan-Meier curve showing OS probability.

Table 2. Overall survival probability according to various groups.

\begin{tabular}{|l|c|c|c|}
\hline \multicolumn{1}{|c|}{ Groups } & OS at 48 months (\%) & Standard error (\%) & $p$-value \\
\hline N0 & 96.3 & 2.5 & \\
N1 & 92.9 & 6.9 & 0.001 \\
N2 & 84.0 & 7.3 & \\
N3 & 63.6 & 10.3 & \\
\hline M0 & 92.1 & 3.1 & 0.001 \\
M1a & 85.8 & 6.6 & \\
M1b & 54.5 & 15 & \\
\hline S0 & 100 & - & 0.001 \\
S1 & 92.7 & 4.1 & \\
S2 & 83.0 & 6.9 & \\
S3 & 46.2 & 13.8 & 0.012 \\
\hline Stage 1 & 100 & - & \\
Stage 1S & 95 & 4.9 & \\
Stage 2 & 86.7 & 8.8 & 0.001 \\
Stage 3 & 78.5 & 5.5 & \\
\hline Good risk & 93.6 & 3.6 & \\
Intermediate risk & 87.5 & 6.8 & \\
Poor risk & 52.6 & 11.5 & \\
\hline
\end{tabular}

The PFS probability was $84.5 \%$ at 48 months (Figure 2). There was no difference in PFS in the presence of a history of cryptorchidism, scrotal violation, presence of LVSI, seminomatous elements, yolk sac components, choriocarcinoma or embryonal carcinoma in the resected specimen or based on T stage. However, there was a significant difference in PFS according to $\mathrm{N}$ stage, M stage, S status, composite stage and IGCCCG risk group (Table 3). 


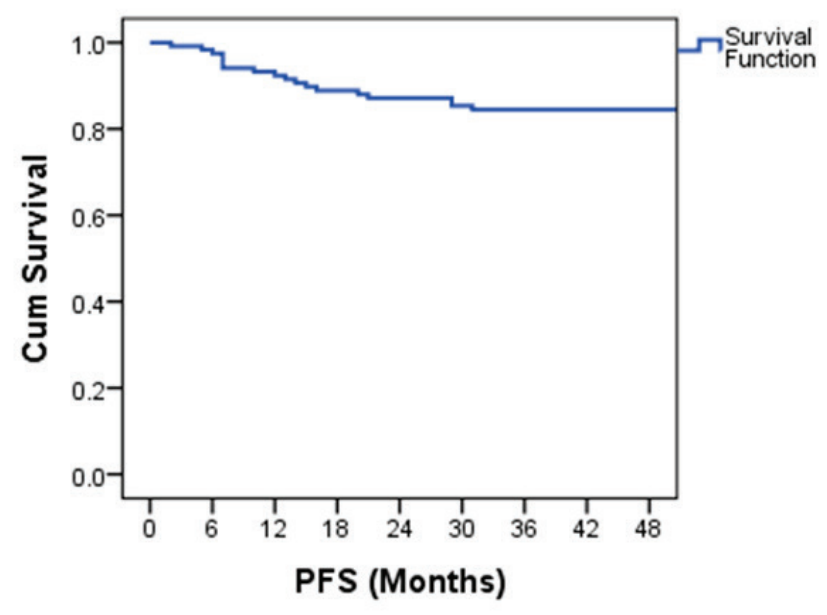

Figure 2. Kaplan-Meier curve showing PFS probability.

Table 3. Progression free survival probability according to various groups.

\begin{tabular}{|l|c|c|c|}
\hline \multicolumn{1}{|c|}{ Groups } & PFS at 48 months (\%) & Standard error (\%) & $p$ value \\
\hline N stage & & & \\
N0 & 92.6 & 3.5 & \\
N1 & 92.9 & 6.9 & 0.001 \\
N2 & 79.8 & 8.1 & \\
N3 & 63.6 & 10.3 & \\
\hline M stage & & & \\
M0 & 90.8 & 3.3 & 0.001 \\
M1a & 82.1 & 7.3 & \\
M1b & 45.5 & 15 & \\
\hline S stage & & & \\
SO & 96.9 & 3.1 & 0.001 \\
S1 & 90.2 & 4.7 & \\
S2 & 82.6 & 7.1 & \\
S3 & 46.2 & 13.8 & \\
\hline Composite stage & & & \\
I & 96.0 & 3.9 & \\
IS & 95.0 & 4.9 & \\
II & 86.7 & 8.8 & \\
III & 74.8 & 5.8 & \\
\hline IGCCCG risk group & & & \\
Good & 91.4 & 4.1 & \\
Intermediate & 87.8 & 6.6 & \\
Poor & 47.4 & & \\
\hline
\end{tabular}


In univariate Cox proportional hazards regression, bHCG values, LDH levels, nodal status, presence of metastases, $\mathrm{S}$ stage, composite stage, IGCCCG risk group and biochemical and radiological response after first-line chemotherapy were significant predictors of survival (Table 4). In multivariate analysis, $M$ stage and biochemical response after first-line chemotherapy remained significant factors for survival.

Table 4. Cox proportional hazard regression model on prognostic factors for OS and PFS.

\begin{tabular}{|c|c|c|c|c|c|c|c|c|}
\hline \multirow{4}{*}{$\begin{array}{c}\text { Factors } \\
\text { Age }(\geq 40 \text { versus }<40)\end{array}$} & \multicolumn{4}{|c|}{ OS } & \multicolumn{4}{|c|}{ PFS } \\
\hline & \multirow{3}{*}{$\begin{array}{c}\text { Hazard ratio (HR) } \\
1.781\end{array}$} & \multicolumn{2}{|c|}{$95 \%$ confidence interval } & \multirow{3}{*}{$\begin{array}{l}p \text { value } \\
0.443\end{array}$} & \multirow{3}{*}{$\begin{array}{c}\text { HR } \\
1.562\end{array}$} & \multirow{2}{*}{\multicolumn{2}{|c|}{$95 \% \mathrm{Cl}$}} & \multirow{3}{*}{$\begin{array}{l}p \text { value } \\
0.551\end{array}$} \\
\hline & & \multirow{2}{*}{$\begin{array}{l}\text { Lower } \\
0.407\end{array}$} & \multirow{2}{*}{$\begin{array}{l}\text { upper } \\
7.790\end{array}$} & & & & & \\
\hline & & & & & & 0.361 & 6.761 & \\
\hline $\begin{array}{l}\text { Cryptorchidism } \\
\text { (yes versus no) }\end{array}$ & 1.086 & 0.144 & 8.187 & 0.937 & 1.213 & 0.162 & 9.091 & 0.851 \\
\hline Scrotal violation (yes versus no) & 25.46 & 0.068 & 9560 & 0.284 & 2.986 & 0.398 & 22.37 & 0.287 \\
\hline $\begin{array}{l}\text { Seminoma components } \\
\text { (no versus yes) }\end{array}$ & 1.302 & 0.458 & 3.697 & 0.620 & 1.439 & 0.547 & 3.788 & 0.461 \\
\hline $\begin{array}{l}\text { Yolk sac elements } \\
\text { (no versus yes) }\end{array}$ & 0.738 & 0.285 & 1.912 & 0.531 & 0.902 & 0.363 & 2.242 & 0.824 \\
\hline $\begin{array}{l}\text { Choriocarcinoma } \\
\text { (no versus yes) }\end{array}$ & 0.410 & 0.054 & 3.094 & 0.387 & 0.365 & 0.049 & 2.732 & 0.326 \\
\hline $\begin{array}{l}\text { Embryonal carcinoma } \\
\text { (no versus yes) }\end{array}$ & 0.669 & 0.258 & 1.733 & 0.408 & 0.672 & 0.273 & 1.655 & 0.387 \\
\hline AFP values ${ }^{a}$ & & & & 0.137 & & & & 0.077 \\
\hline$A 1$ versus $A 0$ & 1.066 & 0.325 & 3.495 & 0.915 & 0.916 & 0.291 & 2.887 & 0.881 \\
\hline$A 2$ versus $A 0$ & 3.326 & 1.013 & 10.919 & 0.048 & 3.372 & 1.131 & 10.05 & 0.029 \\
\hline$A 3$ versus $A 0$ & 3.764 & 0.452 & 31.33 & 0.220 & 3.210 & 0.394 & 26.13 & 0.276 \\
\hline bHCG values ${ }^{b}$ & & & & 0.004 & & & & 0.009 \\
\hline $\mathrm{H} 1$ versusHO & 2.280 & 0.766 & 6.787 & 0.139 & 1.729 & 0.627 & 4.771 & 0.290 \\
\hline $\mathrm{H} 2$ versus $\mathrm{HO}$ & 0 & - & - & 0.985 & 0 & - & - & 0.983 \\
\hline $\mathrm{H} 3$ versus $\mathrm{HO}$ & 10.586 & 2.974 & 37.67 & 0.001 & 8.105 & 2.429 & 27.04 & 0.001 \\
\hline $\mathrm{LDH}^{\text {values }}{ }^{\mathrm{c}}$ & & & & 0.002 & & & & 0.002 \\
\hline L1 versus L0 & 2.214 & 0.405 & 12.087 & 0.359 & 1.778 & 0.345 & 9.166 & 0.491 \\
\hline L2 versus L0 & 4.584 & 1.379 & 15.235 & 0.013 & 4.124 & 1.381 & 12.31 & 0.011 \\
\hline L3 versus LO & 18.427 & 4.099 & 82.832 & 0.001 & 14.850 & 3.530 & 62.47 & 0.001 \\
\hline T stage & & & & 0.470 & & & & 0.590 \\
\hline $\mathrm{T} 2$ versus $\mathrm{T} 1$ & 2.482 & 0.800 & 7.690 & 0.115 & 2.141 & 0.705 & 6.506 & 0.179 \\
\hline T3 versus T1 & 0.991 & 0.129 & 7.620 & 0.993 & 0.840 & 0.110 & 6.387 & 0.866 \\
\hline T4 versus T1 & 0 & - & - & 0.987 & 0 & - & - & 0.986 \\
\hline $\mathrm{N}$ stage & & & & 0.002 & & & & 0.004 \\
\hline N1 versus NO & 1.258 & 0.131 & 12.098 & 0.842 & 0.934 & 0.104 & 8.355 & 0.951 \\
\hline N2 versus NO & 3.017 & 0.675 & 13.492 & 0.148 & 2.882 & 0.773 & 10.74 & 0.115 \\
\hline N3 versus NO & 9.892 & 2.672 & 36.618 & 0.001 & 7.429 & 2.284 & 24.16 & 0.001 \\
\hline
\end{tabular}


Table 4. Cox proportional hazard regression model on prognostic factors for OS and PFS. (Continued)

\begin{tabular}{|c|c|c|c|c|c|c|c|c|}
\hline M stage & & & & 0.001 & & & & 0.001 \\
\hline M1a versus $M 0$ & 2.882 & 0.929 & 8.940 & 0.067 & 2.483 & 0.834 & 7.393 & 0.102 \\
\hline$M 1 b$ versus $M 0$ & 9.152 & 2.784 & 30.00 & 0.001 & 9.276 & 3.108 & 27.67 & 0.001 \\
\hline S stage & & & & 0.003 & & & & 0.004 \\
\hline $\mathrm{S} 2$ versus $\mathrm{S} 1$ & 2.307 & 0.650 & 8.181 & 0.196 & 2.664 & 0.779 & 9.108 & 0.118 \\
\hline $\mathrm{S} 3$ versus $\mathrm{S} 1$ & 7.800 & 2.279 & 26.695 & 0.001 & 7.892 & 2.306 & 27.01 & 0.001 \\
\hline Composite stage & & & & 0.034 & & & & 0.026 \\
\hline Stage II versus I & 6.257 & 0.561 & 69.033 & 0.134 & 3.172 & 0.447 & 22.52 & 0.248 \\
\hline Stage III versus I & 13.119 & 1.724 & 99.832 & 0.013 & 7.052 & 1.611 & 30.86 & 0.010 \\
\hline Risk group & & & & 0.001 & & & & 0.001 \\
\hline Intermediate versus good & 2.752 & 0.615 & 12.316 & 0.185 & 2.043 & 0.510 & 8.179 & 0.313 \\
\hline Poor versus good & 10.194 & 2.754 & 37.737 & 0.001 & 8.512 & 2.664 & 27.20 & 0.001 \\
\hline $\begin{array}{l}\text { Radiological complete response } \\
\text { after 1st line chemo (no versus } \\
\text { yes) }\end{array}$ & 13.558 & 3.097 & 59.352 & 0.001 & 9.803 & 2.853 & 33.68 & 0.001 \\
\hline $\begin{array}{l}\text { Biochemical complete response } \\
\text { after 1st line chemo (no versus } \\
\text { yes) }\end{array}$ & 16.913 & 6.438 & 44.433 & 0.001 & 14.282 & 5.636 & 36.19 & 0.001 \\
\hline
\end{tabular}

aA0- normal AFP values, A1-AFP < 1,000 ng/mL, A2-AFP $\geq 1,000$ and $\leq 10,000 \mathrm{ng} / \mathrm{mL}$, A3-AFP > 10,000 ng/mL

bHO-normal bHCG values, H1-bHCG < 5,000 iu/L, H2-bHCG > $5000 \mathrm{iu} / \mathrm{L} \leq 50,000 \mathrm{iu} / \mathrm{L}, \mathrm{H3}$-bHCG > 50,000 iu/LcL0-normal LDH values, L1-LDH <1.5× upper limit of normal, L2-LDH $\geq 1.5 \times$ upper limit of normal and $\leq 10 \times$ upper limit of normal, L3-LDH > 10× upper limit of normal

Serum AFP and bHCG levels, LDH values, $\mathrm{N}$ stage, M stage, S stage, composite stage, IGCCCG risk group, biochemical and radiological response after first-line chemotherapy were significant factors for PFS in univariate Cox proportional hazards regression. M stage, biochemical and radiological response after chemotherapy remained significant on multivariate analysis also.

\section{Discussion}

The incidence of testicular germ cell tumours is low in the Indian population. There is a paucity of Indian data on the epidemiology and treatment outcomes of this rare cancer. Hence, we conducted this retrospective analysis of nonseminomatous germ cell tumours of testis treated at a Regional Cancer Centre in South India.

The median age at presentation was 27 years (17-53 years) which is similar to that reported in the literature [7], though a few studies have reported a median age above 30 years [8,9]. Cryptorchidism is associated with an increased risk of testicular germ cell tumours [10]. In our series, seven patients (5.8\%) developed the disease in the undescended testis; five of them were surgically corrected during childhood. The incidence is less when compared to previously published Indian data, where $12.5 \%$ of tumours developed in the undescended testis [11]. The incidence of undescended testis in our part of the world is probably decreasing, as seen from our previous publications [12, 13]. Presence of LVSI is considered as an independent prognostic factor for recurrence in stage I nonseminomatous tumours [14], but due to the limited data on LVSI, it was not assessed in this study. 
About half of the patients in our series presented with stage III disease. Other reported series from India has published a similar proportion of patients with NSGCT in advanced stages [3-5]. Only $27 \%$ of patients presented with stage I (IA and IB) disease. Of these, only three patients were placed on active surveillance which is very less compared to the western literature [15, 16]. This may be due to the poor compliance noticed in our young male population. Even though RPLND is an accepted adjuvant treatment for stage I NSGCT, none of our patients underwent primary RPLND.

Among patients with metastatic disease, $38.3 \%$ had good risk disease and $26.02 \%$ of patients were in the poor-risk category. This is similar to most of the published literature where the majority of the patients were categorised as good-risk group [17, 18]. The proportion of poor-risk patients is comparable to previously published Indian data also [3, 4].

Biochemical complete response was seen in $89 \%$ of patients after first-line chemotherapy. However, only $58 \%$ of patients achieved a complete radiological response. Thirty-nine patients had the residual paraaortic nodal disease after first-line chemotherapy, but only 14 patients underwent RPLND. The rates of post-chemotherapy RPLND were less in our series compared to some previously published data [18, 19]. Many of our patients refused surgery, considering the likely complications such as retrograde ejaculation and the need for major vascular repair.

Ten patients received second-line chemotherapy on recurrence or progression, the regimens being Paclitaxel, Ifosfamide and Cisplatin (TIP), Etoposide, Ifosfamide and Cisplatin (VIP) and Vinblastine, Ifosfamide and Cisplatin (VeIP). Several salvage chemotherapy regimens have been tried in tumours refractory to BEP and TIP [20, 21]. High-dose chemotherapy and stem-cell transplantation are considered an effective option for relapsed germ cell tumours [22, 23]. In this study, none of the patients was salvaged with high-dose chemotherapy and stem-cell transplantation.

The four-year OS and PFS were $87.1 \%$ and $84.5 \%$, respectively. Survival was $100 \%$ for stage 1 patients. The four-year survival for IS, II and III were $95 \%, 86.7 \%$ and $78.5 \%$, respectively. The survival rates are better compared to the previously published Indian data [4, 5]. Among the patients with metastatic disease, four-year OS was $93.6 \%, 87.5 \%$ and for $52.6 \%$ for good, intermediate and poor-risk groups, respectively. The PFS at four years was $91.4 \%, 87.8 \%$ and $47.4 \%$ for good-, intermediate- and poor-risk NSGCT, respectively. These figures are comparable to the data published by IGCCCG [6]. Due to the advances in chemotherapy and stem-cell transplantation in the salvage setting, the outcomes of poor-risk patients have improved over the years. The five-year survival has improved up to 70\% in some studies [7, 17, 19]. The 5 -year PFS ranges from $54 \%$ to $58 \%$ in those studies [7, 17]. However, our salvage options were limited, and hence the survival of poor-risk patients remains low.

Age greater than 40 years was found to be associated with increased mortality in germ cell tumours [16, 17]. However, in our study, age was not related to outcome. Only nine patients were aged $>40$ years, and that may be the reason for the nonsignificant association. Cryptorchidism and scrotal violation had no association with survival in the present study similar to other studies [4]. Presence of embryonal carcinoma and LVSI was thought to be associated with increased risk of recurrence in stage I NSGCT [14]. We could not find any association of embryonal carcinoma with PFS or OS, and LVSI was not assessed due to incomplete data. Presence of seminoma, choriocarcinoma and yolk sac elements did not influence survival in this study similar to the study reported by Heinzelbecker et al [24].

Many studies have established the role of serum biomarkers in predicting response and survival $[6,25,26]$. In univariate analysis, serum tumour marker levels, namely, AFP, beta HCG, LDH values, were significant predictors of OS and LDH, BHCG values for PFS. An increasing nodal size was reported as a negative prognostic factor in many studies $[4,26]$. $\mathrm{N}$ stage was found to be a significant predictor for OS and PFS in this study as well.

Nonpulmonary visceral metastasis has been established as a negative prognostic factor for survival in many studies [6, 19]. This finding was confirmed in this study also. The most important prognostic factor reported in the majority of the studies was risk group [4, 6]. The patients in the poor- and intermediate-risk groups had a higher risk of progression or death compared to those in the good-risk group.

The limitations of the study are its retrospective nature, the limited data on LVSI and chemotherapy toxicities as well as lack of information on fertility issues after treatment. 
Majority of the testicular cancers are diagnosed at an advanced stage in India. Early detection can be achieved with awareness programmes for both general practitioners and the public. High-risk patients should be referred to specialised high-volume centres to improve outcomes. All these high-volume centres should be equipped with provision for high-dose chemotherapy and stem-cell transplantation.

\section{Conclusion}

This is the second-largest retrospective series on NSGCT from India with good follow-up information. The survival figures are comparable to the rest of the world except in the poor prognostic risk group. The inferior survival noticed in this group of patients may be due to the lack of good salvage procedures, which is mainly due to the limitation of resources. Hence high-dose chemotherapy with stem-cell support may be considered more often for this group of patients.

\section{Source of funding}

None.

\section{Conflicts of interest}

None.

\section{References}

1. Manecksha RP and Fitzpatrick JM (2009) Epidemiology of testicular cancer BJU Int 104(9 B) 1329-1333 https://doi.org/10.1111/ j.1464-410X.2009.08854.x PMID: 19840008

2. Shanmugalingam T, Soultati A, and Chowdhury S, et al (2013) Global incidence and outcome of testicular cancer Clin Epidemiol 5(1) 417-427 PMID: 24204171 PMCID: 3804606

3. Joshi A, Zanwar S, and Shetty N, et al (2016) Epidemiology of male seminomatous and nonseminomatous germ cell tumors and response to first-line chemotherapy from a tertiary cancer center in India Indian J Cancer 53(2) 313-316 https://doi.org/10.4103/0019$\underline{509 \times .197741}$

4. Saju SV, Radhakrishnan V, and Ganesan TS, et al (2019) Factors that impact the outcomes in testicular germ cell tumors in low-middleincome countries Med Oncol 36(3) 28 https://doi.org/10.1007/s12032-019-1252-6 PMID: 30725328

5. Bhutani M, Kumar L, and Seth A, et al (2002) Germ cell tumours of the testis: clinical features, treatment outcome and prognostic factors Natl Med J India 15(1) 18-21 PMID: 11855586

6. Mead GM (1997) International germ cell consensus classification: a prognostic factor- based staging system for metastatic germ cell cancers J Clin Oncol 15(2) 594-603 https://doi.org/10.1200/JCO.1997.15.2.594

7. Adra N, Althouse SK, and Liu H, et al (2016) Prognostic factors in patients with poor-risk germ-cell tumors: a retrospective analysis of the Indiana University experience from 1990 to 2014 Ann Oncol 27(5) 875-879 https://doi.org/10.1093/annonc/mdw045 PMID: 26861605 PMCID: 4843188 
8. Kojima T, Kawai K, and Tsuchiya K, et al (2015) Identification of a subgroup with worse prognosis among patients with poor-risk testicular germ cell tumor Int J Urol 22(10) 923-927 https://doi.org/10.1111/iju.12844 PMID: 26094715

9. Bhatti $\mathrm{ABH}, \mathrm{Ahmed} \mathrm{I}$, and Ghauri RK, et al (2014) Clinical profile, treatment and survival outcome of testicular tumors: a Pakistani perspective Asian Pacific J Cancer Prev 15(1) 277-280 https://doi.org/10.7314/APJCP.2014.15.1.277

10. Banks K, Tuazon E, and Berhane K, et al (2013) Cryptorchidism and testicular germ cell tumors: comprehensive meta-analysis reveals that association between these conditions diminished over time and is modified by clinical characteristics Front Endocrinol (Lausanne) 3(February) 1-11 https://doi.org/10.3389/fendo.2012.00182

11. Sarma D, Barua SK, and Rajeev TP, et al (2913) Role of primary chemotherapy in management of large tumors of undescended testis: our experience Urol Ann 5(3) 179-182 https://doi.org/10.4103/0974-7796.115742

12. James FV, Mathew A, and Anand RK (2005) Testicular seminoma: review of 67 cases from India J Clin Oncol 23(16_suppl) 4783 https:// doi.org/10.1200/jco.2005.23.16_suppl.4783

13. Anjanappa M, Kumar A, and Mathews S, et al (2017) Testicular seminoma: are clinical features and treatment outcomes any different in India? Indian J Cancer 54(1) 385-387 https://doi.org/10.4103/ijc.IJC_100_17 PMID: 29199728

14. Lago-Hernandez CA, Feldman H, and O'Donnell E, et al (2015) A refined risk stratification scheme for clinical stage 1 NSGCT based on evaluation of both embryonal predominance and lymphovascular invasion Ann Oncol 26(7) 1396-1401 https://doi.org/10.1093/ annonc/mdv180 PMID: 25888612 PMCID: 4553701

15. Sturgeon JF, Moore MJ, and Kakiashvili DM, et al (2011) Non-risk-adapted surveillance in clinical stage I nonseminomatous germ cell tumors: the Princess Margaret Hospital's experience Eur Urol 59(4) 556-562 https://doi.org/10.1016/j.eururo.2010.12.010

16. Dong P, Liu ZW, and Li XD, et al (2013) Risk factors for relapse in patients with clinical stage I testicular nonseminomatous germ cell tumors Med Oncol 30(1) https://doi.org/10.1007/s12032-013-0494-y PMCID: 3586391

17. Ataergin S, Ozet A, and Arpaci F, et al (2007) Outcome of patients with stage II and III nonseminomatous germ cell tumors: results of a single center Indian J Cancer 44(1) 6-11 https://doi.org/10.4103/0019-509X.31161 PMID: 17401218

18. Nakamura T, Ueda T, and Oishi M, et al (2015) Importance of continuous sequential chemotherapy and multimodal treatment for advanced testicular cancer Med (United States) 94(11) e653

19. Albany C, Adra N, and Snavely AC, et al (2018) Multidisciplinary clinic approach improves overall survival outcomes of patients with metastatic germ-cell tumors Ann Oncol 29(2) 341-346 https://doi.org/10.1093/annonc/mdx731 PMCID: 6248648

20. Pectasides D, Pectasides M, and Farmakis D, et al (2004) Oxaliplatin and irinotecan plus granulocyte-colony stimulating factor as third-line treatment in relapsed or cisplatin-refractory germ-cell tumor patients: a phase II study Eur Urol 46(2) 216-221 https://doi. org/10.1016/j.eururo.2004.03.001 PMID: 15245816

21. Nishikawa M, Miyake H, and Fujisawa M (2016) Irinotecan and nedaplatin as salvage therapy for patients with advanced germ cell tumors following intensive treatment with cisplatin-based combination chemotherapies Int J Clin Oncol 21(1) 162-167 https://doi. org/10.1007/s10147-015-0861-0

22. Popovic L, Matovina-Brko G, and Popovic M, et al (2015) High dose chemotherapy with stem cell support in the treatment of testicular cancer World J Stem Cells 7(11) 1222-1232

23. Voss MH, Feldman DR, and Motzer RJ (2011) High-dose chemotherapy and stem cell transplantation for advanced testicular cancer Expert Rev Anticancer Ther 11(7) 1093-1105 https://doi.org/10.1586/era.10.231 
24. Heinzelbecker J, Katzmarzik M, and Weiss C, et al (2013) During twenty years of cisplatin-based therapy the face of nonseminomatous testicular germ cell tumors is still changing: an evaluation of presentation, management,predictive factors and survival Int Braz J Urol 39(1) 10-21 https://doi.org/10.1590/S1677-5538.IBJU.2013.01.03 PMID: 23489512

25. Dieckmann KP, Simonsen-Richter H, and Kulejewski M, et al (2019) Serum tumour markers in testicular germ cell tumours: frequencies of elevated levels and extents of marker elevation are significantly associated with clinical parameters and with response to treatment Biomed Res Int 20195030349 https://doi.org/10.1155/2019/5030349 PMID: 31275973 PMCID: 6558624

26. Necchi A, Pond GR, and Nicolai N, et al (2017) A suggested prognostic reclassification of intermediate and poor-risk nonseminomatous germ cell tumors Clin Genitourin Cancer 15(2) 306-312.e3 https://doi.org/10.1016/j.clgc.2016.07.022 